\title{
DEVELOPING A HEALTH OUTCOMES FRAMEWORK FOR WOMEN
}

\section{Elena Murty}

Senior Policy Analyst, Women's Health

Health Services Policy Branch

NSW Department of Health

\section{Mary Osborn}

Formerly of the Health Services Policy Branch Currently at United Medical Protection, North Sydney

A changing focus of accountability in government from inputs to and outputs from health services, to health outcomes, has led to an increasing emphasis on the measurement and assessment of the effect of interventions on the health of individuals and whole populations. This article describes a project of the NSW Department of Health to develop a framework to both expand the current methods for monitoring women's health outcomes, and for

\section{NSW PUBLIC HEALTH BULLETIN}

The NSW Public Health Bulletin is a publication of the NSW Department of Health. The editor is Dr Lynne Madden, Manager, Public Health Training and Development Unit, NSW Department of Health. Dr Michael Giffin is production manager.

The Bulletin aims to provide its readers with population health data and information to motivate effective public health action.

\section{Submission of articles}

Articles, news and comments should be 1000 words or less in length and include a summary of the key points to be made in the first paragraph. References should be set out in the Vancouver style, described in the New England Journal of Medicine, 1997; 336: 309-315. Send submitted articles on paper and in electronic form, either on disc (Word for Windows is preferred), or by email. The article must be accompanied by a letter signed by all authors. Full instructions for authors are available on request from the editor.

\section{Editorial correspondence}

Please address all correspondence and potential contributions to The Editor, NSW Public Health Bulletin, Locked Mail Bag 961, North Sydney NSW 2059 or to Lmadd@doh.health.nsw.gov.au. Tel (02) 9391 9956, Fax (02) 93919232.

\section{Distribution}

Please contact your local Public Health Unit or telephone (02) 93919942 to obtain copies of the NSW Public Health Bulletin or to notify us of a change of address. The Bulletin can be accessed via the Internet from the Department's Web site: www.health.nsw.gov.au/ public-health/phb/phb.html.

Back issues can be obtained from the Public Health Training and Development Unit, Locked Mail Bag 961, North Sydney NSW 2059. measuring health outcomes for women. Founded on the Strategic Framework to Advance the Health of Women (draft), ${ }^{1}$ the Women's Health Outcomes Project will consult with key stakeholders, conduct information forums across NSW, and produce a discussion paper.

The project was developed as a result of findings within a report conducted on behalf of the Australian Health Minister's Advisory Committee sub-committee on women's health. ${ }^{2}$ This report suggests that social determinants need to be recognised as influencing health outcomes for women and should be monitored as part of the pathway in measuring women's health status. This supports the fact that the women's health sector has always developed interventions which recognise the relationship between socio-economic status and health. ${ }^{3,4}$

There is widespread recognition that factors such as income, education and employment have a significant influence on morbidity and mortality. ${ }^{5}$ These factors are known as socio-economic determinants of health. Socioeconomic status influences the differential health outcomes of groups in society expressed as rates of disability, chronic disease and use of the health system. ${ }^{6}$ Gender-defined as the roles, characteristics, responsibilities and expectations that our society ascribes to being male or female-is another determinant.

The draft Strategic Framework to Advance the Health of Women provides the foundation and guiding principles for developing the health outcomes framework. The Women's Health Outcomes Project will illustrate the interaction between social and biological determinants of health, and how the health system can measure the outcomes of interventions developed to address the effect of the social determinants of women's health.

Any health outcomes framework must be grounded in the National Women's Health Policy, ${ }^{5}$ have the capacity to assess gender-specific outcomes over non-reproductive and reproductive areas of health, and that differences between groups of women be measured and explained. ${ }^{7}$

The health system has a valid role to play in action and advocacy to address the full range of potentially modifiable social determinants of health that are reflected in health inequalities. This will necessitate working with women, other agencies, and government departments to address, in particular, the health of those women with the poorest health outcomes. The framework will identify what health outcomes for women are to be measured, how they will be measured, and why.

\section{REFERENCES}

1. NSW Department of Health. The Strategic Framework to Advance the Health of Women in NSW. Unpublished draft, December 1999.

2. Sansoni J, Rubenstein L. Women's Health Outcomes: a consultancy undertaken for the AHMAC sub-committee on women and health. December 1996. (Unpublished). 
3. Commonwealth Department of Community Services and Health. National Women's Health Policy: Advancing Women's Health in Australia. Canberra: Australian Government Publishing Service, 1989.

4. Commonwealth of Australia, Sub-committee on Women and Health Australian Health Minister's Advisory Council. Health Goals and Targets for Australian Women. Canberra: Australian Government Publishing Service,1993.
5. Dixon J. Health Inequities Research Collaboration Framework. Canberra: National Centre for Epidemiology and Population Health, Australian National University, 1999.

6. Wilkinson R and Marmot M (eds). The Solid Facts: Social Determinants of Health. New York: World Health Organization., 1989.

7. Tilley, L (1996) Australian Health Outcomes Clearing House: Measuring Women's Health Outcomes - Gender Differences and Implications for Health Practice, November 1996. (Unpublished). $\mathbf{F}$

\section{GENDER EQUITY IN HEALTH}

Andrew Gow and Elena Murty

Health Services Policy Branch

NSW Department of Health

There is international and local recognition that social and economic factors play a significant role in determining health and well being. ${ }^{1,2,3}$ Recent policy developments by NSW Health in men's and women's health have been based on this recognition. This has led to the recent release of Moving Forward in Men's Health, ${ }^{4}$ and the soon to be released Strategic Framework to Advance the Health of Women. ${ }^{5}$ Both of these policy statements have also clearly recognised that gender is a social determinant of health.

The relationship between gender and health is often poorly understood. In an attempt to clarify this issue, the Department of Health is developing Gender Equity in Health. ${ }^{6}$ This document defines four key concepts:

- gender

- gender equity

- gender equality

- gender analysis.

It includes two checklists to be used as a tool to assist policy makers and service managers integrate these concepts into their work.

Gender Equity in Health explicitly states that gender equity is not another name for sex differentials. Sex differentials are essentially comparisons between men and women of factors such as health status and service usage. The effect of gender on health is generally not measured while sex differentials are. Sex differentials are often used to provide an indication (although an imperfect one) of the effect of gender and the need for gender equity.

Gender is a social construction. It refers to those roles, characteristics, responsibilities and expectations that our society ascribes as being male or female. Gender is socially determined, while sex is biologically determined. Gender equity, then, is a concept that recognises the differences in opportunities that are caused by gender, and brings about a range of strategies that aim to achieve fairness and justice in the distribution of the benefits and responsibilities. Gender equity is not about treating everyone the same. Rather, a gender equity approach involves examining which groups of women and which groups of men have poorer health outcomes than others. Different approaches may be required to attain equitable outcomes.

Gender equality is a more tangible concept. It is defined as the absence of discrimination, on the basis of sex rather than gender, in opportunities and the allocation of resources, benefits or access to services.

In order to encourage an improved understanding of the effect of gender on health, policy makers and service managers are encouraged to undertake gender analysis. This methodology analyses differences in opportunities, needs, incentives, circumstances, health status and quality of life in women and men. Gender analysis can be used to redress gender biases in policy, program design, management, implementation and review.

Gender Equity in Health will encourage a gender equity approach to health service policy planning and delivery across NSW.

\section{REFERENCES}

1. Wilkinson R and Marmot M (eds). Social Determinants of Health: The Solid Facts. Copenhagen: World Health Organization, 1998.

2. Royal Australasian College of Physicians. For richer, for poorer, in sickness and in health. Sydney: RACP, 1999.

3. Commonwealth Department of Health and Aged Care. (1999). Health Policy and Inequality. Canberra: Occasional Papers Unit, 1999.

4. NSW Department of Health. Moving Forward in Men's Health. Sydney: NSW Department of Health, 1999.

5. NSW Department of Health. Strategic Framework to Advance the Health of Women. Unpublished draft, 1999.

6. NSW Department of Health. Gender Equity in Health. Unpublished draft, 1999. it

Copies of Gender Equity in Health can be obtained from the Better Health Centre by telephoning (02) 98160452 and quoting publication number (HSP)000015; or from the Health Web site at www.health.nsw.gov.au. 